IOSR Journal of Pharmacy

ISSN: 2250-3013, www.iosrphr.org

||| Volume 2 Issue 5 ||| Sep-Oct. 2012 ||| PP.23-30

\title{
Dendrimers as potential platform in nanotechnology-based drug delivery systems
}

\author{
SILVA JR, N. P. ${ }^{1}$, MENACHO F. P. ${ }^{1}$, CHORILLI, M. ${ }^{2}$ \\ 1(Enviromental and Educational Faculty FAEMA, Av. Machadinho, 4349, CEP: 78932-000, \\ Ariquemes, RO, Brazil) \\ 2 Department of Drugs and Pharmaceuticals, UNESP, São Paulo State University, Rodovia \\ Araraquara-Jaú, km 1, Araraquara, SP 14801-902, Brazil)
}

\begin{abstract}
The dendrimers of poly (amidoamine) (PAMAM) are nanoparticles which have proven succeed in transporting drugs due to high solubility, low toxicity and ability to control drugs release. Studies have explored the biological potential of dendrimers such as to transport genes, development of vaccines, antiviral, antibacterial and anticancer therapies. This review of literature on the PAMAM dendrimers discusses the architecture and general construction of dendrimers and intrinsic properties of the PAMAM. This study also describes how the PAMAM interact with many drugs and the potential of these macromolecules as well as drug nanocarriers in transdermal routes of administration, ocular, respiratory, oral and intravenous administration. Dendrimers promises good future prospects for the biomedicine.
\end{abstract}

Keywords-Dendrimers, Nanocarriers, PAMAM Poly (amidoamine), Pharmaceutical application

\section{INTRODUCTION}

About $40 \%$ of all drugs developed by the pharmaceutical industry are rejected because they are unable to obtain real therapeutic benefits as a result of the low permeability of cell membranes or very poor solubility in water, reducing bioavailability [1]. Side effects from drugs therapy are consequences of administration of conventional drugs that when reaching the target, eventually reaching other body sites not related to the disease. However, with advances in nanotechnology and other drug problems make these solutions the era of nanotechnology drugs, since they are produced with a special structure for releasing the drug in its target site to confer selectivity [2]. Furthermore, the nanoparticles smart facilitate passage through biological barriers, potential obstacles for the free drug [3]. Among the latest generations of nanosystems are dendrimers that constitute potential drug carriers [4]. These highly symmetrical and branched polymers have attracted much attention in recent years due to their specific physical and chemical properties arising from its organized construction [5]. Among the dendrimers contemporary skilled in the delivery of functional molecules are dendrimers poly (amidoamine) (PAMAM), which have been studied in drug formulations like antinflammatory, antimicrobial, antiviral, anticancer [6]. This study is justified by increasing production of scientific research on the PAMAM, since the ability of these polymers to improve the physical and chemical characteristics of the drugs with intrinsic problems. This literature has therefore scoped contribute as a source of knowledge about some of the therapeutic applications of PAMAM. In this literature review the first part will present the dendrimers through the general definition, description of their constituents and structural synthesis methods. While in the second step occurs an explanation of the PAMAM specifying about their synthesis, properties, toxicity, pegylation and the types of drugs incorporation in the dendrimer. Lastly, examples are given of how PAMAM can aid in drug administration by various routes.

\section{DENDRIMERS GENERAL STRUCTURE}

Dendrimers are also known as arboróis, cascade molecules, or highly branched polymers and have been casually discovered by Vogtle and colleagues in 1978 [7]. Dendrimers are polymeric molecules, chemically synthesized with well defined shape, size and nanoscopic physicochemical properties reminiscent of the proteins [8]. These polymers are almost spherical shape tree having diameters generally between 2 and 10 $\mathrm{nm}[9,10]$.

From the chemical point of view, because they are synthetic, the dendrimerscould be from a peptide, lipid, polysaccharide, among other variations [4]. These new structures represent a true revolution in chemistry because of its extremely precise and controlled architecture, giving it a predictable molecular weight, biodegradability and biocompatibility [11]. 
The dendrimer structure is a further topology found in nature. It may be observed not only in abiotic systems, for example, snow crystals and the shape of lightning but also in the biological world, such as neurons, branches and tree roots in addition to the vascular systems of animals [12,9]. The dendrimers can be basically divided into three regions: center, branches and surface area $[13,14,15]$.

The core determines the shape, size, direction and multiplicity of dendrimers. The middle part is formed by the branching units and functional groups of terminals are macromolecular periphery [16]. Traditionally, the dendrimers are synthesized by branching units, the monomers $\mathrm{ABn}$, which results in a symmetrical with the end groups B [17]. The constituents of dendrimers have $A B n n \geq 2$, but typically $n=2$ and 3 , in other words after each addition of monomers which are arranged in layers around the dendrimer, can be double or triple the number of peripheral groups $[18,19,20]$.

Identical monomer units bind repeatedly around a core by means of branch points, sequentially building tree architecture of the polymer [21, 22].The prepared monomers forming layers after each addition in the core, resembling the layers of an onion from the inside to outside arranged in three dimensions. Each of these layers between the concentric core and the periphery is called generation [23, 24].The generation dendritic rises every additional interaction through a sequence of steps consisting of repetitive reactions. Each new synthesized layer becomes a new generation, usually twice as active sites or surface groups and the molecular weight almost doubled compared to the predecessor generation [25, 26]. There may still be a division of the peripheral groups and internal branches of the dendrimer branching into real arms. Such structures are called dendrons and are in large segments branching units radiating from the core functional $[27,28]$.

The surface of the dendrimer may be formed by passive or reactive terminal groups to perform a variety of functions. Region serving as a polymerization in which each generation is covalently bonded to generate the precursor [29]. The surface groups may function as gates that control the entry and exit of guest molecules from the interior of the dendrimer. These properties also enables better control and biodistribution of the drug by the body $[11,15]$.

\subsection{Synthesis of dendrimers}

There are two main schemes of synthesis, which are convergent and divergent strategies for growth $[30,31]$. In the divergent approach the growth during synthesis begins at the core in a process that is directed radially to the periphery. The process convergent dendrimer growth begins at the periphery directing the production of synthesis inside [32, 33]. As the two methodologies have advantages and disadvantages, the most appropriate choice will depend mainly on the type of monomer used in the architecture of the polymer target [34]. Unlike the convergent method, the purity and structural uniformity of the products are more difficult to achieve in the divergent approach, since the number of responses that must be completed for each growth stage increases exponential rate, which requires large amounts of reagents. This method is more suitable for production in large scale $[32,35]$.

The divergent method consists of a growth from the core of the dendrimer where branching is produced by a repetitive series of steps of adding and activation, rapidly multiplying the number of branches [33, 36].The core molecule interacts with the molecule of the monomer having a reactive group and two groups are not reactive, yielding a zero generation dendrimer $(\mathrm{G} 0)$. Then the new molecular surface is activated for reactions with more monomers [37]. This process can be repeated for several generations [10].The divergent synthesis ends by the addition of functional groups in the branch points the last generation of branches. This iterative process leads to congestion due to the numerous end groups on the dendrimer periphery [38].

The dendrimer is produced by a multifunctional initiator core that reacts with chemically activated focal point (Y) of a branched monomer to synthesize the dendrimers first generation. Higher generation are built by the addition of monomers branched iteratively producing a dendrimer terminated with full chemical functional groups [39].

\subsection{PAMAM dendrimer}

Poly (amidoamine) (PAMAM) is the most widely studied and characterized, and so the better understood so far. Extensive literature on this polymer focuses on biomedical properties [40, 41]. The structure of PAMAM dendrimers starts from a molecule of ammonia $\left(\mathrm{NH}_{3}\right)$ or ethylenediamine $\left(\mathrm{C}_{2} \mathrm{H}_{8} \mathrm{~N}_{2}\right)$ as a core which binds to amine groups of branches $\left(\mathrm{R}_{-} \mathrm{NH}_{2}\right)$ and amide $\left(-\mathrm{CONH}_{2} \mathrm{R}\right)$ [7, 37].PAMAM dendrimers are biocompatible, water-soluble non-immunogenic and have amine functional groups that are modifiable to enable the connection with guest molecules or target. Through the PAMAM cavities present on its architecture this dendrimer can host various molecules since the presence of amines and amides groups in its skeleton allows such interaction [42]. However, these polymers may have other functional groups in addition to the amine, such as carboxyl and hydroxyl groups, which grows with generations increasing [43]. In addition, each new generation, PAMAM dendrimer doubles the number of functional groups and weight also increases in $1 \mathrm{~nm}$ diameter of its structure $[22,23]$.

PAMAM dendrimers are synthesized by divergent method, based on a construction divided into stages in the presence of methanol, around the nucleus chosen, which could be ammonia or ethylenediamine. The two 
sequences of steps consisting in (1) alkylation of the amine functional core with methyl acrylate, also known as Michael addition, generating two branches intermediate with ends ester [26]. Following the amidation occurs (2) the esters with ethylene diamine to produce the generation zero (G0) with four terminal amine groups. Similarly, reaction of this intermediate with ethanolamine produces branched (G0) with four $\mathrm{OH}$ surface groups [39]. The consecutive repetition of Michael additions with methyl acrylate and ethylenediamine yields amidation with a dendrimer (G1) and higher generations, increasing the size, weight and number of end groups of the dendrimer[42]. The reaction may stop in step addition of methyl acrylate. The methyl ester can undergo hydrolysis, thus generating an intermediate generation dendrimer or half generation $(\mathrm{G} \mathrm{0.5),} \mathrm{(G} \mathrm{1.5)} \mathrm{and} \mathrm{so} \mathrm{on,}$ with $\mathrm{COOH}$ anionic groups [44].

The dendrimers growth becomes gradually thick and its periphery with a closed structure similar to a membrane. This state of critical branching is achieved when the dendrimer, for lack of space, can no longer grow. This phenomenon is called starburst effect, being observed in PAMAM dendrimers after the tenth generation $[10,18,27]$.

\subsection{Properties of PAMAM dendrimers}

\subsubsection{Monodispersivity, size and shape}

The monodispersion means that the dendrimers has a well defined molecular structure and without large individual variations, in other words, they are homogeneous unlike other polymers due to their controlled synthesis and purification processes. Such control facilitates the research, because it becomes a tool with defined size ranges [45]. The advantage of low polydispersity makes it possible to predict the pharmacokinetic behavior of dendrimers because little variation of molecules weight makes it possible to know the sample movements of these polymers for biological organism [46].

Due to their nanometric scales and other properties that are similar to proteins, dendrimers are also known as artificial proteins and gain attention in studies that make use of their biomimetic properties [40]. The dendrimer can be controlled by molecular engineering so that its size resembling to antibodies, enzymes and globular proteins. The core PAMAM dendrimer generation ammonia 3, 4 and 5 are close in size and shape of insulin $(30 \AA)$, cytochrome $\mathrm{C}(40 \AA)$ and hemoglobin $(55 \AA)$, respectively. Because of the similarity with these and other molecules dendrimers can travel efficiently through the body [47].

In the production of PAMAM dendrimers of generation 1 and 10 the diameter of dendrimers with ethylene diamine core grows from 1.1 to $12.4 \mathrm{~nm}$. As this may vary in shape according to the generation, as the generations (G0) to (G3) with ethylenediamine core in ellipsoid shape but the high generation of (G4) to (G10) takes spheroidal form [48]. This is because the dendrimer spreads segments as possible to reduce the repulsion which leads to a globular structure [26].The early generations of the PAMAM dendrimer(G0) and (G1) have highly asymmetric forms and open structures compared with higher generations [49].

\subsubsection{Polivalency}

The polivalency is related to the quantity of reactive sites on outside of the dendrimer potential to form connections with various materials of interest [50]. Areas of high multivalent dendrimers of generations can contain a large number of functional groups. This makes the surface of the dendrimer branches and more susceptible to interactions with a large number of species [43].

The multivalencyallows better interaction with biological targets since most of the molecular interactions occur through biological multivalent bonds. The valency binder is the number of links that can be established with a receiver or receivers. The strength of multivalent interactions exceeds the sum of the forces [38].

Dendrimers as potential platform in nanotechnology-based drug delivery systems exhibit higher biological activity compared to conventional drug molecules because the dendrimer can react with multiple receivers at once in the biological site of action [51].

\subsubsection{Solubility and biocompability}

Dendrimers generally have greater solubility in common solvents as compared to linear polymers [30]. However, the solubility depends on various components in addition to the surface groups as the generation number, nature of repeating units and even the core. What enables the construction of dendrimers perfectly soluble in a large number of solvents, ensuring both the solubility of dendrimers in organic solvents, which leads a rapid dissolution in water and enhances the activity of hydrophobic molecules [48]. PAMAM dendrimers have received considerable attention because its ability to solubilize water-insoluble drugs and transporting them through the biomembranes, increasing the bioavailability of these drugs [52, 53].

Before being used as biological agents in drug delivery, dendrimers should meet a variety of requirements such as: (1) having no toxicity, (2) is not immunogenic (3) ability to cross biological barriers such as the walls and the intestinal membranes, (4) remain in circulation long enough to be effective clinically (5) ability to deliver specific structures $[54,55]$. The biological properties as, for example, immunogenicity and toxicity depends mainly on the size and the surface groups of the dendrimers. The interior structure therefore 
has less influence because usually the dendrimer interactions occur with the outside via the exposed surface groups, which makes the dendrimers able to cross cell surfaces [16].

\subsection{Toxicity and pegylation}

It is known that the dendrimers may cause toxicity mainly attributed to the interaction of the cationic dendrimers surface with negative biological load membranes damaging cellular membranes causing hemolytic toxicity and cytotoxicity. Therefore, PAMAM dendrimers are more cationic than anionic cytotoxic. An example of interaction with lipid bilayers of cells occurs with the cationic dendrimer-G7 PAMAM which comes to form holes $15-40 \mathrm{~nm}$ in diameter, which disturbs the flow of electrolyte causing cell death [24, 56, 44].Many toxic effects of dendrimers are attenuated at their surfaces with hydrophilic molecules and poly (ethylene glycol) (PEG) which masks the surface charge cationic dendrimersimproving biocompatibility and increasing the solubility of the polymers. The pegylateddendrimers have lower cytotoxicity and longer stay in the blood than non-pegylateddendrimers. PEGylation increases the physical dendrimers size which reduces renal clearance since the glomerular filtration limit is reached $[1,57,58]$.

\subsection{Interactions of drugs with dendrimers}

The dendrimers designed for drug delivery have the intention to improve the pharmacokinetics and biodistribution of drugs and may also provide a controlled release of the drug with the goal of reaching the target tissues [59]. Dendrimers interact with drug molecules physically by absorption on surface by electrostatic interactions or by conjugation with the surface groups for covalent bonding or by encapsulation of the drug into the cavities of the dendrimer $[60,61,62]$.

The technique of drugs encapsulation may be a purely physical entrapment or involve interactions with specific structures within the dendrimer [63]. The empty internal cavities generally have hydrophobic propertieswhich allow interactions with poorly soluble drugs. The existence of atoms of nitrogen and oxygen in the internal structure of the dendrimer allows interaction by hydrogen bonds with the drug [48].Encapsulation is a general strategy for low molecular weight molecules and are transported on the bioactive surface of dendrimers induce undesired immunogenicity [49].

The high density of functional groups are ionizable at the periphery of the dendrimer (such as amines and carboxyl groups) permits to fix a large number of ionizable drugs by electrostatic interactions and transporting them to their destination [63, 64]. Covalent interaction method offers advantages over previous methods, therefore allow multiple drugs to be attached to each dendrimer through the numerous groups of the surface, the covalent bonds between the drug and the polymer are likely more difficult to break giving them greater control over the drugs, overcoming the force of interaction achieved by electrostatic bonds and encapsulation $[34,59]$.

\subsection{PAMAM applications in drug delivery}

Dendrimers can be designed to improve the properties of some drugs in ocular, pulmonary, oral, intravenous,topical and transdermal formulations. TheTable 1 presents the applications of PAMAM dendrimers in various routes.

\begin{tabular}{|l|l|l|l|l|}
\multicolumn{1}{|l}{ PAMAM } & Drugs & \multicolumn{2}{c|}{ Routes } & \multicolumn{2}{c|}{ References } \\
\hline G5-PAMAM & Ketoprofen and & Transdermal & {$[65]$} \\
\hline G4-PAMAM & Indomethacin & & {$[66]$} \\
\hline $\begin{array}{l}\text { G2-G6- } \\
\text { PAMAM }\end{array}$ & 5-fluorouracil & Topic & {$[67]$} \\
\hline $\begin{array}{l}\text { G3-PAMAM } \\
\text { G5-PAMAM }\end{array}$ & Nifedipine & & {$[52]$} \\
\hline $\begin{array}{l}\text { G2-G3- } \\
\text { PAMAM }\end{array}$ & Ketoconazole & & {$[68]$} \\
\hline $\begin{array}{l}\text { G1.5-4- } \\
\text { PAMAM }\end{array}$ & $\begin{array}{l}\text { Pilocarpine nitrate } \\
\text { and tropicamide }\end{array}$ & Ocular & {$[69]$} \\
\hline G3.5-PAMAM & $\begin{array}{l}\text { Glucosamine and } \\
\text { Glucosamine 6- } \\
\text { sulfate }\end{array}$ & $\begin{array}{l}\text { Brimonidine and } \\
\text { timolol maleate }\end{array}$ & & {$[70]$} \\
\hline G3-PAMAM & $\begin{array}{l}\text { Enoxaparin } \\
\text { G2-G3- } \\
\text { PAMAM }\end{array}$ & $\begin{array}{l}\text { Insulin } \\
\text { calcitonin }\end{array}$ & {$[71]$} \\
\hline $\begin{array}{l}\text { G0-G3- } \\
\text { PAMAM }\end{array}$ & & {$[72]$} \\
\hline
\end{tabular}


Dendrimers as potential platform in nanotechnology-based drug delivery systems

\begin{tabular}{|l|l|l|l|}
\hline G3-PAMAM & Propranolol & Oral & {$[74]$} \\
\hline G5-PAMAM & Ketoprofen & & {$[75]$} \\
\hline G0-PAMAM & Naproxen & & {$[76]$} \\
\hline $\begin{array}{l}\text { G0-G3- } \\
\text { PAMAM }\end{array}$ & Niclosamina & & {$[77]$} \\
\hline G3-PAMAM & Sulfamethoxazole & & {$[78]$} \\
\hline $\begin{array}{l}\text { G0-G3- } \\
\text { PAMAM }\end{array}$ & Furosemide & & {$[79]$} \\
\hline G4-PAMAM & Risperidone & & {$[80]$} \\
\hline G4-PAMAM & Flurbiprofen & Intravenous & {$[81]$} \\
\hline G4-PAMAM & Indomethacin & & {$[82]$} \\
\hline G4-PAMAM & 5-fluorouracil & & {$[83]$} \\
\hline G3.5-PAMAM & Cisplatin & & {$[84]$} \\
\hline G5-PAMAM & Methotrexate & & {$[85]$} \\
\hline
\end{tabular}

\section{Source: Adapted from above authors}

Dendrimers can be designed to improve the properties of some drugs in topical and transdermal formulations delivering the drug to its destination due to the increased permeation of drug through the skin [86, 87, 88]. Due to its properties, the dendrimers can be used as carriers in the effective ophthalmic drug delivery, since they can suffer from low bioavailability because of the physiological barriers belonging to the eye [89, 90].

The pulmonary route provides a large surface area for delivery of drugs in addition to avoiding first pass metabolism by increasing the systemic bioavailability of the top and become more effective therapeutic action [91]. However, the potential of dendrimers in pulmonary drug delivery still remains as an avenue that needs further research [92]. The oral route is the most popular and acceptable by the patient. Because of this, several studies involving dendrimers have emerged in order to improve the oral absorption of drugs [93, 58].

The intravenous route is not only a simple method also presents itself as the simplest way of delivering a drug to the systemic circulation. However, the low solubility of various drugs has been an important limiting factor for a better use of the intravenous route [94].

\section{CONCLUSIONS}

PAMAM dendrimers are presented as nanocarriers drugs promising for the coming years, since the multiple properties related to their three-dimensional structure, as mono dispersity, versatility, biocompatibility and other characteristics intrinsic which increase the solubility and activity of these drugs linked these polymers, improving the bioavailability and reduce the toxicity potential of many drugs. The drug can be linked to the dendrimers by covalent bonds, electrostatic interactions, or by encapsulation, and the choice of the interaction fits the drug needs. Furthermore, as a flexible and excellent carrier, the dendrimers can be carefully designed for the delivery of biomolecules to the desired target tissue, which allows the use of lower doses, although effective in therapy. However, dendrimers PAMAM accept various routes of administration, which increases the range of drugs maybe enhanced action in the body which have limited application process options. This versatility can facilitate in the future the safe use of drugs which cannot be used in medicine for reasons of toxicity or low solubility.

\section{REFERENCES}

[1]. SVENSON, Sonke. Dendrimers versatile platform in the drug delivery applications.European Journal of Pharmaceutics and Biopharmaceutics, USA, 71(3), 2009, 445-462.

[2]. $\quad$ POLETTO, Fernanda S.; POHLMANN, Adriana R.; GUTERRES, Sílvia S. Uma pequena grande revolução. Ciência hoje, 43(255), 2008, 26-31.

[3]. BERGMANN, Bartira Rossi. A nanotecnologia: da saúde para além do determinismo tecnológico. Ciência e Cultura, São Paulo, 60(2), 2008, 54-57.

[4]. OSUNA, Irene Bravo; VANRELL, Rocio Herrero. Potencial de dendrímeros como vehículos de fármacos em oftalmologia. Archivos de La SociedadEspañola de Oftalmología,Madrid, 82(2), 2007, 60-70.

[5]. GURTOVENKO, Andrey A. et al. Dynamics of dendrimer-based polymer networks. Journal of Chemical Physics, 119(14), 2003, 7579-7590.

[6]. BAWARSKI Willie E. et al. Emerging nanopharmaceuticals. Nanomedicine: Nanotechnology, Biology and Medicine, U.S.A, 4(4), 2008, 273-282.

[7]. VIVAS, Marcelo Gonçalves. Utilização de espectroscopia de ressonância de plásmon de superfície na investigação das propriedades hemocompatíveis do dendrímero PAMAM, dissertação (Mestrado em Ciências dos Materiais para Engenharia) - Instituto de Ciências, Universidade Federal de Itajubá, Itajubá, 2007. 
[8]. GONZALO, Teresa; MUÑOZ-FERNÁNDEZ, Ángeles. Dendrímeros y susaplicaciones biomédicas, monografía XXVIII: Nanotecnología farmacêutica. Madrid: Real Academia Nacional de Farmácia, 2009.

[9]. TOMALIA, Donald A. et al. Dendrimers as reactive modules for the synthesis of new structure-controlled, highercomplexity megamers. Pure and Applied Chemistry, Michigan, 72(12), 2000, 2343-2358.

[10]. KLAJNERT, Barbara; BRYSZEWSKA, Maria. Dendrimers: properties and applications. ActaBiochimica Polonica, Poland, 48(1), 2001, 199-208.

[11]. OLIVEIRA, Joaquim Miguel et al. Dendrimers and derivatives as a potential therapeutic tool inregenerative medicine strategies - A review. Progress in Polymer Science,USA, 35(9), 2010, p. 1163-1194.

[12]. TOMALIA, Donald A.; FRÉCHET, Jean M. J. Discovery of dendrimers and dendritic polymers: a brief historical perspective. Journal of Polymer Science: Part A: Polymer Chemistry, USA, 40(16), 2002.

[13]. LEE, C. Cameron et al. Designing Dendrimers for biological applications. Nature Biotechnology, 23(12), 2005, 1517-1526.

[14]. BALZANI, Vincenzo. Dendrimers: order, complexity, functions. Australian Journal of Chemistry, Australia, 64(2), 2011, 129-130.

[15]. TOMALIA, Donald A.; CHRISTENSEN, Jorn B. Dendrimers as Quantized Nano-Modules in the Nanotechnology Field. IN: CAMPAGNA, Sebastiano; CERONI, Paola (Eds.). Designing dendrimers. USA: John Wiley \& Sons, Inc., 2012. p. 1-33.

[16]. MARCOS, Mercedes; SERRANO, José Luis. Polímeros dendríticos. Anales de La Real Sociedade Espñola de Química, 105(2), 2009, 103-110.

[17]. ORNELAS, Catia et al. Construction of a well-defined multifunctional dendrimer is theranostics. Organic Letters,13(5), 2011, 976-979.

[18]. SECO, MiquelÀngel; ANGURELL, InmaculadaPurroy. ElsDendrimersl'molecular aesthetically.Revista de La CatalanaSocietat Chemistry, Barcelona, 5, 2004, 27-37.

[19]. FLOMENBOM, Ophir et al. Some New Aspects of dendrimer applications. Journal of Luminescence, 111(4), 2005, 315-325.

[20]. PAIM, Leonardo Lataro. Preparation, characterization and use of nanostructured materials supported on silica gel, dissertation (MSc in Materials Science) - Faculty of Engineering of Single Island, UniversidadeEstadualPaulista, 2007.

[21]. GINGRAS, Marc; RAIMUNDO, Jean-Manuel; CHABRE, Yoann M. Cleavable. Dendrimers. Angewandte ChemieInt International Edition, 46(7), 2007, 1010-1017.

[22]. MENJOGE, Anupa R.; KANNAN, M. Rangaramanujam; TOMALIA, Donald A. Dendrimer-based imaging and drug conjugates: design considerations for nanomedical applications. Drug Discovery Today, 15(5/6), 2010, 171185.

[23]. JATO, Jose Luis Vila. Nanotecnologia farmacêutica: una galénica emergente, discurso delExcmo. Sr. D. Jose Luis Vila Jato. Instituto deespaña. Real academia national defarmácia. Madrid, 2006.

[24]. CRAMPTON, Hannah L.; SIMANEK, Eric E. Dendrimers the drug delivery vehicles: non-covalent interactions of bioactive compounds with Dendrimers. Polymer International, Texas, 56(4), 2007, 489-496.

[25]. HOLISTER, Paul; VAS, Cristina Roman; HARPER, Tim. Dendrimers. Cienífica, 2003, 15

[26]. NANJWADE, Basavaraj K. et al. Dendrimers: Emerging polymers for drug-delivery systems. European Journal of Pharmaceutical Sciences, 38(3), 2009, 185-196.

[27]. SEKOWSKI, Szymon; MILOWSKA, Katarzyna; GABRYELAK, Teresa. Dendrimers in biomedical sciences and nanotechnology.PostepyHig Med Dosw,Poland, 62, 2008, 725-733.

[28]. VOGTLE, Fritz; RICHARDT, Gabriele; WERNER, Nicole. Dendrimer Chemistry: Concepts, Syntheses, Properties, Applications. 1 ed. USA: Wiley-VCH Verlag GmbH \& Co., 2009. 354.

[29]. TOMALIA, Donald A. Dendrons / Dendrimers: quantized, like nano-element building blocksfor soft-soft and softhard nano-compound synthesis. Soft Matter, Michigan, 6(3), 2010, 456-474.

[30]. INOUE, K. Functional Dendrimers, hyperbranched and star polymers. Progress in Polymer Science,USA, 25(4), 2000, 453-571.

[31]. SCHOLL, Markus; KADLECOVA, Zuzana; KLOK, Harm-Anton.Dendritic and hyperbranched polyamides. Progress in Polymer Science,34(1), 2009, 24-61.

[32]. FRÉCHET, Jean M. J. Dendrimers and supramolecular chemistry. Proceedings of the National Academy of Sciences of the United States of America,USA, 99(8), 2002, 4782-4787.

[33]. ZAUPA, Giovanni. MultivalentiSistemi per la catalisiCooperativi and biomimetics.Doctoral diss., UniversitàdegliStudi di Padova, Padova, 2008.

[34]. AULENTA, Francesca; HAYES, Wayne; RANNARD, Steven. Dendrimers: a new class of nanoscopic containers and delivery devices. EuropeanPolymerJournal,UnitedKingdom, 39(9),2003, 1741-1771.

[35]. TASSANO, Marcos. Dendrímeros marcados $\operatorname{con}^{99 \mathrm{~m}} \mathrm{Tc}$ como possibleradiofármaco para el diagnóstico de procesostumorales, monografia (Licenciatura em Biologia) - Facultad de Ciencias, Universidad de la República, Montevideo, 2008.

[36]. ZHANG, L. et al. Development of nanoparticles for antimicrobial drug delivery. Current Medicinal Chemistry,CA, 17(6), 2010, 585-594.

[37]. VIEIRA, NirtonCristi Silva. Biossensores de glicosenanoestruturadosbaseadosemdendrímeros PAMAM e filmesfinos de $\operatorname{In}_{2} \mathrm{O}_{3}$, dissertação (Master of Science in Materials Engineering) - Institute of Exact Sciences, Federal University of Itajubá, 2006.

[38]. HAYDER, Myriam. Anti-Inflammatory Properties of Dendrimers per se. The World Scientific Journal, 11, 2011, 1367-1382. 
[39]. MEDINA, Scott H., EL-SAYED, Mohamed E. H. Dendrimers carriers for the delivery of chemotherapeutic agents. Chemical Reviews,109(7), 2009, 3141-3157.

[40]. TOMALIA, Donald A. et al. Dendrimers - An Enabling Synthetic Science to Controlled Organic Nanostructures. In: GODDARD III, William A.; LYSHEVSKI, Sergey Edward (Eds.). Handbook of Nanoscience, engineering, and, technology. Washington: CRC Press LLC, 2002.

[41]. TOMALIA, Donald A. Birth of a new macromolecular architecture: Dendrimers the quantized building blocks for nanoscale synthetic organic chemistry. Aldrichimica ACTA, Michigan, 37(2), 2004, 39-57.

[42]. PATRI, Anil K; MAJOROS, Istvan J., BAKER JR, James R. Dendritic macromolecular polymer carriers for drug delivery. Current Opinion in Chemical Biology, Michigan, 6(4), 2002, 466-471.

[43]. ARAÚJO, Luciana Pires de Campos Mattoso. Dendrímeros como carreadores de protoporfirina IX para a terapia fotodinâmica tópica do câncer de pele,doctoral diss., FacultyofPharmaceuticalSciencesof Ribeirão Preto, Universidade de São Paulo, Ribeirão Preto, 2010.

[44]. SZYMA'NSKI, Pawel; MARKOWICZ, Magdalena; MIKICIUK-OLASIK, Elz • bieta. Nanotechnology in pharmaceutical and biomedical applications.Dendrimers.World Scientific Publishing Company,California, 6(6), 2011, 509-539.

[45]. KUMAR, Peeyush. et al. Dendrimer: a novel polymer for drug delivery. JournalofInnovativeTrends in PharmaceuticalSciences, 1(6), 2010, 252-269.

[46]. SILVA, Alexandra Rodrigues Pereira. Estudo das propriedades bioquímicas de sistemas poliméricos arborescentes PGLD-AAS para o tratamento de câncer, dissertação (Master of Science in MaterialsEngineering) - Instituteof Science, Universityof Itajubá, Itajubá, 2008.

[47]. MAJOROS, Istvan J.; BAKER, James R. Dendrimer-based Nanomedicine.1.USA: Pan Stanford Publishing Pte. $2008,440$.

[48]. CHENG, Yiyun et al. Dendrimers the drug carriers: applications in different routes of drug administration. Journal of Pharmaceutical Sciences, 97(1), 2008, 123-143.

[49]. SAMPATHKUMAR, Srinivasa-Gopalan; YAREMA, Kevin J. Dendrimers in Cancer Diagnosis and Treatment. IN: Kumar, Challa (Ed.). Nanomaterial is Cancer Diagnosis. Baton Rouge: WILEY-VCH Verlag GmbH \& Co. KGaA, 2007, 1-43.

[50]. MUKHERJEE, Swarupananda; PATRA, SwapanSandip; Sarkar, Dhrubajyot. Dendrimers: A novel approach in nano drug delivery. NSHM Journal of Pharmacy and Healthcare Management, 2, 2011, 51-60.

[51]. PRESTIDGE, Clive; Griesser, Hans; BARNES, Tim. Interfacial properties of Dendrimers for improved pharmaceutical activity. Australian Postgraduate Research, School of Pharmacy, University of south Australia.

[52]. DEVARAKONDA, Bharathi; LI, Ning; VILLIERS, M. Melgardt. Effect of polyamidoamine (PAMAM) Dendrimers on the in vitro release of nifedipine from water-insoluble aqueous gels.AAPS PharmSci Tech, 6(3), 2005, 504-512.

[53]. CHAUHAN, Abhay Singh et al. Solubility enhancement of poorly water soluble molecules using Dendrimers. Material Matters,2(1), 2007, 24-27.

[54]. FAKHRNABAVI Hassan. Dendrimers the building blocks for nanoscale synthesis. Journal of Applied Chemical Researches, Tehran, 3(12), 2010, 25-28.

[55]. SCHULZ, Michael. Recent Advances in the use of the Dendrimers vehicles for drug delivery (Florida: University of Florida), 2011, 13

[56]. KIM, Tae-il et al. Comparison Between arginine conjugated PAMAM Dendrimers with Structural diversity for gene delivery systems. Journal of Controlled Release, Republic of Korea, 136(2), 2009, 132-139.

[57]. MCNEIL, Scott E. Nanoparticle therapeutics: a personal perspective. Wiley Interdisciplinary Reviews: Nanomedicine and Nanobiotechnology, 1(3), 2009, 264-271.

[58]. KAMINSKAS, Lisa M.; BOYD, Ben J., PORTER, Christopher JH. Dendrimer pharmacokinetics: the effectof size, structure and surface characteristics on ADME properties.Nanomedicine, London, 6(6), 2011, 1063-1084.

[59]. WOLINSKY, Jesse B.; GRINSTAFF, Mark W. Therapeutic and diagnostic applications of Dendrimers for cancer treatment. Advanced Drug Delivery Reviews, USA, 60(9), 2008, 1037-1055.

[60]. GAREA, Alexandra Sorina; GHEBAUR, Adi; ANDRONESCU, Corina. Systems based on Dendrimers and antitumor drug synthesized by non-covalent method. Materia le plastice, Bucharest, 48(1), 2011, 17-22.

[61]. INA, Mishra. Dendrimer: a novel drug delivery system. Journal of Drug Delivery \& Therapeutics, India, 1(2), 2011, 70-74.

[62]. LEE, Jun H.; NAN, Anjan. Combination drug delivery approaches in metastatic breast cancer. Journal of Drug Delivery,New York, 2012, 2012, 1-17.

[63]. GARG, Tarun et al. Dendrimer - a novel scaffold for drug delivery. International Journal of Pharmaceutical Sciences Research and Review, 7(2), 2011, 211-220.

[64]. SHISHU, Goindi; MAHESHWARI, Manjul. Dendrimers: The novel pharmaceutical drug carriers. International Journal of Pharmaceutical Sciences and Nanotechnology, Hyderabad, 2(2), 2009, 493-502.

[65]. CHENG, Yiyun et al. Transdermal delivery of nonsteroidal anti-inflammatory drugs mediated by polyamidoamine (PAMAM) Dendrimers. Journal of Pharmaceutical Science, 96(3), 2007, 595-602.

[66]. CHAUHAN, Abhay Singh et al. Dendrimer-mediated transdermal delivery: enhanced bioavailability of indomethacin. Journal of Controlled Release, 90(3), 2003,335-343.

[67]. VENUGANTI, VenkataVamsi K.; PERUMAL, Omathanu P. Poly (amidoamine) Dendrimers the skin penetration enhancers: Influence of charge, generation, and concentration. Journal of Pharmaceutical Sciences, 98(7), 2009, 2345-2356. 
[68]. WINNICKA, Katarzyna et al. Hydrogel of ketoconazole and PAMAM Dendrimers: formulation and antifungal activity. Molecules,Basel, 17(4), 2012, 4612-4624.

[69]. VANDAMME, Th F.; Brobeck, L. Poly (amidoamine) Dendrimers the ophthalmic vehicles for ocular delivery of pilocarpine nitrate and tropicamide. Journal of Controlled Release, 102(1), 2005, 23-38.

[70]. SHAUNAK, Sunil et al. Polyvalent dendrimer glucosamine conjugates Prevent scar tissue formation. Nature Biotechnology, 22, 2004, 977-984.

[71]. HOLDEN, Christopher A. et al. Polyamidoaminedendrimer hydrogel is enhanced delivery of antiglaucoma drugs. Nanomedicine: Nanotechnology, Biology and Medicine, 2011.

[72]. SHUHUA Bai; CHANDAN, Thomas; FAKHRUL, Ahsan. Dendrimers as a carrier for pulmonary delivery of enoxaparin, a low-molecular weight heparin.Journal of Pharmaceutical Sciences, 96(8), 2007, 2090-2106.

[73]. DONG, Zhengqi et al. PolyamidoamineDendrimers Can Improve the pulmonary absorption of insulin and calcitonin in rats. Journal of Pharmaceutical Sciences, 100(5), 2011, 1866-1878.

[74]. D'EMANUELE, Antony et al. The use of a dendrimer-propranolol prodrug to bypass efflux transporters and Enhance oral bioavailability. Journal of Controlled Release, 95(3), 2004, 447-453.

[75]. MAN, Na et al. Dendrimers the potential drug carriers. Part II. Prolonged delivery of ketoprofen by in vitro and in vivo studies.European Journal of Medicinal Chemistry,41(5), 2006, 670-674.

[76]. NAJLAH, Mohammad et al 2007. In vitro evaluation of dendrimerprodrugs for oral drug delivery.International Journal of Pharmaceutics,336(1), 2007, p. 183-190.

[77]. DEVARAKONDA, Bharathi et al. Comparison of the aqueous solubilization of Practically insoluble niclosamide by polyamidoamine (PAMAM) Dendrimers and cyclodextrins. International Journal of Pharmaceutics, 304(1-2), 2005, 193-209.

[78]. MA, Minglu et al. Evaluation of polyamidoamine (PAMAM) Dendrimers the drug carriers of anti-bacterial drugs using sulfamethoxazole (SMZ) as a model drug. European Journal of Medicinal Chemistry,42(1), 2007, 93-98.

[79]. DEVARAKONDA, Bharathi et al. Effect of $\mathrm{pH}$ on the solubility and release of furosemide from polyamidoamine (PAMAM) dendrimer complexes. International Journal of Pharmaceutics, 345(1-2), 2007, p. 142-153.

[80]. PRIETO, MaríaJimenaet al. Optimization and in vitro evaluation of toxicity G4 PAMAM dendrimer-risperidone complexes. European Journal of Medicinal Chemistry,46(3), 2011, 845-850.

[81]. ASTHANA, Abhay et al. Poly (amidoamine) (PAMAM) dendritic nanostructures for controlled site-specific delivery of acidic anti-inflammatory active ingredient. AAPS Pharm Sci Tech, India, 6(3), 2005, 536-542.

[82]. CHAUHAN, Abhay Singh et al. Solubility Enhancement of Indomethacin with Poly (amidoamine) Dendrimers and Targeting to Inflammatory Regions of Arthritic Rats. Journal of Drug Targeting, 12(9-10), 2004, 575-583.

[83]. BHADRA, D. et al. A PEGylated dendritic nanoparticulate carrier of fluorouracil.International Journal of Pharmaceutics, 257(1-2), 2003, 111-124.

[84]. MALIK, N.; Evagorou, E. G, Duncan, R. Dendrimer-platinate: A novel approach to cancer chemotherapy. Anticancer Drugs,10(8), 1999, 767-776.

[85]. KUKOWSKA-LATALLO, Jolanta F. et al. Nanoparticle targeting of anticancer drug Improves therapeutic response in animals model of human epithelial cancer. American Association for Cancer Research, Philadelphia, 65(12), 2005, 5317-5324.

[86]. TOLIA, Gaurav T.; CHOI, Hannah H. The Role of Dendrimers in Topical Drug Delivery.Find Pharma, 32(11),2008, 88-98.

[87]. PATIDAR, Ajay; THAKUR, Devendra Singh. Dendrimers: potential carriers for drug delivery. International Journal of Pharmaceutical Sciences and Nanotechnology Bilaspur, 4(2), 2011, 1383-1389.

[88]. JANA, Sougata et al. Dendrimers: synthesis, properties, and drug delivery biomedical applications. American Journal of Research Pharmtech, USA, 2(1), 2012, 32-55.

[89]. GAUDANA, Ripal al. Recent et perspectives in ocular drug delivery. Pharmaceutical Research, 26(5), 2009, 1197 1216.

[90]. HARIKUMAR, S. L; SONIA, Arora. Nanotechnological approaches in ophthalmic delivery systems. International Journal of Drug Development \& Research, India, 3(4), 2011, 9-19.

[91]. SADHNA, Sharma; SINGH, Amandeep. Nanotechnology based Targeted Drug Delivery: Current Status and Future Prospects for Drug Development. IN: Kapetanovic, Izet (Ed.). Drug Discovery and Development - Present and Future. [S.1.]: In Tech, 2011, 427-462.

[92]. MANSOUR, Heidi M.; RHEE, Yun Seok; WU, Xiao. Nanomedicine in pulmonary delivery.International Journal of Nanomedicine, Princeton, 4, 2009, 299-319.

[93]. GAJBHIYE, Virendra et al. Dendrimericnanoarchitectures mediated transdermal and oral delivery of bioactives. Indian Journal of Pharmaceutical Sciences, India, 70(4), 2008, p. 431-439.

[94]. BRANNON-PEPPAS, Lisa; BLANCHETTE, James O. Nanoparticle and targeted systems for cancer therapy. Advanced Drug Delivery Reviews, 56(11), 2004, 1649-1659. 